\title{
“TÁ RINDO DE QUÊ?": DISCURSOS E PRODUÇÃO DE SENTIDOS EM ADELAIDE, ZORRA TOTAL
}

\author{
"WHAT ARE YOU LAUGHING AT?": DISCUSSION AND \\ PRODUCTION OF SENSES IN ADELAIDE, ZORRA TOTAL
}

“¿DE QUÉ TE RIEES?”: DISCURSOS Y PRODUCCIÓN

DE SENTIDOS EN ADELAIDE, ZORRA TOTAL

Bruno Marcelo Costa[i]

Paulo Nunes[ii]

Vânia Torres [iii]

\section{RESUMO}

Este texto concentra-se na discussão sobre televisão, mais especificamente na personagem Adelaide, apresentada no programa humorístico Zorra Total, da Rede Globo de Televisão. $O$ artigo parte da premissa de que a televisão ainda é o principal meio de comunicação utilizado pelos brasileiros, sendo pertinente destacar seu papel social e ideológico na construção de sentidos e significados. Portanto, propomos analisar as produções de significado provocadas/emergidas pelo caráter de Adelaide da televisão humorística. Para tanto, utilizaremos como contribuição teórica pensadores de três áreas temáticas, a saber: para apresentar e discutir a televisão com um meio de comunicação predominante no Brasil, utilizaremos os escritos de Dominique Wolton (1996); ainda em discursos televisivos, também é importante dialogar com Niklas Luhmann (2005), que tratará da construção da realidade a partir desses discursos/imagens gerados pela mídia; para trazer uma discussão sobre humor e riso, usamos Henri Bergson (2001) e,

\section{ABSTRACT}

This text aims to discuss about television, more specifically on the character Adelaide, present in the tv comedy show Zorra Total, aired by Rede Globo de Televisão. The article starts from the premise that television is still the main means of communication used by Brazilians, so it is pertinent to highlight its social and ideological role in the construction of meanings and meanings. Therefore, we propose to analyze the productions of meaning provoked/emerged by the Adelaide character of the humorous television. Theorists from three different thematic areas has contributed to this study. First, in order to present and discuss television with a predominant means of communication in Brazil, Dominique Wolton (1996) has based us on the writings. Still, on television speeches, it is also important to dialogue with Niklas Luhmann (2005), whose studies approach the construction of reality from these discourses/images generated by the media. Henri Bergson (2001) guide us in order to develop some

\section{RESUMEN}

Este texto se concentra en la discusión sobre la televisión, más específicamente sobre el personaje de Adelaide, presente en el programa humorístico Zorra Total, de la Rede Globo de Televisión. El artículo parte del punto de vista de que la televisión sigue siendo el principal medio de comunicación utilizado por los brasileños, por lo que es importante destacar su papel social e ideológico en la construcción de sentidos y significados. Por lo tanto, proponemos analizar las producciones de significado propuestas por el personaje de Adelaide de la televisión humorística. Para ello, utilizaremos como contribución teórica pensadores de tres áreas temáticas, a saber: para presentar y discutir sobre la televisión con un medio predominante de comunicación en Brasil, utilizaremos los escritos de Dominique Wolton (1996); todavía en los discursos televisivos, también es importante dialogar con Niklas Luhmann (2005), quien se ocupará de la construcción de la realidad a partir de estos discursos/imágenes generados 
no terceiro eixo temático, negritude no espaço televisivo, estamos baseados em Stuart Hall (2016) e Joel Zito Araújo (2000). Como metodologia de pesquisa, caminharemos no referencial teórico da análise de discurso, fazendo um corte de dois episódios do personagem listado.

\section{Palavras-chaves:}

Televisão; Humor; Negritude; Discurso discussion about humor and laughter. Finally, in the third thematic axis,Stuart Hall (2016) and Joel Zito Araújo (2000) based our writings on blackness in television space As a research methodology, we walk in the theoretical framework of discourse analysis of two episodes of the character Adelaide.

\section{Keywords:}

Television, Humor; Blackness; speech. por los medios de comunicación; para llevar una discusión sobre el humor y la risa, utilizamos Henri Bergson (2001), y en el tercer eje temático, negritud en el espacio televisivo, nos basamos en Stuart Hall (2016) y Joel Zito Araújo (2000). Como metodología de investigación, caminaremos en el marco teórico del análisis del discurso, haciendo un recorte de dos episodios del personaje enumerado.

\section{Palabras clave:}

Televisión, Humor; Negritud; Discurso.

\section{INTRODUÇÃO}

Apesar do avanço da internet e de outros meios de comunicação de massa, podemos afirmar que 0 brasileiro ainda tem a televisão como principal meio de acesso à informação (BRASIL, 2015)[1]. Na maioria dos lares brasileiros, a televisão ainda se faz presente como momento/ritual de união dos familiares em torno de uma notícia que interage de maneira coletiva com essas pessoas. Esse "ritual" nos acompanha desde meados dos anos 60 do século $X X$, desde que a televisão, enquanto aparelho e meio de comunicação, tornouse mais presente nos lares brasileiros. É certo que isso tem se modificado com o advento das mídias sociais, mas ainda percebemos muita influência nos discursos que emergem a partir dela.

Pensar a televisão como principal mecanismo da sociedade para adquirir informação é também pensar como os discursos televisivos se constituem e o modo como essas informações são veiculadas com o intuito de revelar e desvelar algumas práticas discursivas. Nesse sentido, a televisão tem um poder de construção de realidade que merece destaque e um estudo reflexivo e aprofundado, de fôlego. Essa construção da realidade socia se dá de maneira complexa, no entanto, podemos observar, de maneira mais clara, a partir do momento em que os discursos vérbico-visual e tecnológico da televisão são capazes de influenciar jeitos de ser e estar no mundo, os programas de televisão geralmente veiculam sonhos e maneiras de ser. No Brasil, onde o investimento do regime militar de 64 investiu fortemente no aparato de difusão televisiva, estas influências tem um alcance ainda significativo; neste contexto chama atenção a questão etnicorracial. Kellner (2001) nos diz que a mídia conforma identidades, preconiza jeitos de ser "negro" ou "branco", jeitos de ser mulher ou homem, jeitos de ser bemsucedido e malsucedido. Dessa forma, esses 'jeitos de ser' constroem realidades outras a partir do momento que esses discursos adentram os lares brasileiros.

Tratando-se especificamente do discurso humorístico veiculado pela televisão, é importante que se ressalte o caráter colonialista das imagens e do discurso que é utilizado. Lançando mão, frequentemente, da premissa de que no humor tudo é permitido, muitas vezes, as questões éticas e morais são subestimadas e até mesmo minimizadas pelo risível. No caso da população negra brasileira, o que vemos são recortes de uma marginalidade e de uma imagem caricatural da figura do negro. Para nos 
aprofundarmos na temática, certamente teríamos que elencar uma série de argumentos sócio históricos, mas nos concentraremos, neste texto, no discurso velado de inferioridade e subalternidade, estratégias ideológicas de que as elites lançam mão a fim de expressar seus preconceitos.

Desse modo, nesse artigo, propomos analisar quais as produções de sentidos provocadas/emergidas pela personagem "Adelaide", do humorístico Zorra Total, da Rede Globo de Televisão. Para tanto, utilizaremos como aporte teórico pensadores de três áreas temáticas, a saber: para a apresentar e discutir a televisão com meio de comunicação predominante no Brasil, recorremos aos escritos de Dominique Wolton (1996); ainda sobre discursos provocados pela televisão, é importante também dialogar com Niklas Luhmann (2005), que trata da realidade nos meios de comunicação a partir desses discursos/imagens gerados pela mídia; a fim de suscitar uma discussão sobre humor e riso, trazemos Henri Bergson (2001); e, no terceiro eixo temático, negritude no espaço televisivo, nos ancoramos em Stuart Hall (2013; 2016) e Joel Zito Araújo (2000).

Para dar conta do que propomos, este texto parte especificamente da análise do discurso proposta por Eni Orlandi (2001). Nossa análise concentra-se em um personagem humorístico da maior emissora de televisão do Brasil (BRASIL, 2015).

O artigo analisou dois episódios elencando, especificamente, o quadro da personagem em questão. Primeiramente, apresentamos a televisão como meio de comunicação e formadora de discursos; logo em seguida, trazemos a discussão de humor e riso no tópico "Negritude na TV: o borramento[2] entre o riso e o risível", no qual já apresentamos algumas considerações acerca da representação da negritude no humor e, por fim, a análise da personagem Adelaide a partir de uma perspectiva imagética e também discursiva que estão entrelaçadas com questões sócio históricas.

\section{TELEVISÃo E PRODUÇÃO DE SENTIDOS}

De acordo com Wolton (1996, p.67) "A televisão é um espetáculo de um gênero particular, destinado a um público imenso, anônimo e heterogêneo, inseparável de uma programação que garante uma oferta quase contínua de imagens de gêneros e status diferentes". Desde sua gênese é inegável que a televisão vem exercendo influência nos hábitos sociais e culturais das sociedades nas quais ela é utilizada como uma das principais ferramentas para aquisição de informação, conhecimento e entretenimento É também importante dizer que os discursos emanados da televisão são tidos muitas vezes como "legítimos", gerando uma espécie de norma de conduta naquele contexto social. Percebíamos isso com mais clareza quando o "rito" de assistir televisão era um hábito coletivo nos lares brasileiros, o que gerava uma discussão coletiva não única, mas una sobre quase os mesmos assuntos e temáticas. A teoria de laço social defendida por
Dominique Wolton (1996) preconiza isso.

É fato que desde os anos 60 do século $X X$, a televisão conquistou espaço na vida dos telespectadores brasileiros (dadas as devidas relativizações e novas formas de mídias). Hoje, ela acompanha a rotina diária. As pessoas almoçam na hora do jornal, lancham na hora da novela, conversam sobre o que assistiram nos programas e discutem $O$ que viram nos jornais. Mesmo os que não gostem de televisão ou não têm tempo, é muito difícil que não saibam o que aconteceu ontem na novela, o que o jornal mostrou, pois provavelmente encontrarão alguém que vai tratar dos assuntos veiculados no dia anterior. Isso configura uma espécie de realidade paralela, criada em torno dos discursos e imagens televisivos. A televisão, desta forma, produz sentido, dentre outras coisas, a partir de uma realidade ficcional recortada da realidade cotidiana.

Como já dito anteriormente, apesar da quantidade de inovações tecnológicas que permeiam o cotidiano do homem contemporâneo, no Brasil, a televisão ainda é a mídia mais presente. De acordo com Wolton (1996) em seus mais de cinquenta anos de história no país, ela acumulou diferentes sentidos "utilitários" que vão desde instrumento político de integração nacional (anos 60/70) a eletrodoméstico-símbolo da estabilização econômica (anos 90). Em todos esses sentidos, a preocupação primeira da TV nacional sempre foi a conquista da audiência (consumidores de seus produtos). 
Portanto, neste tópico, a intenção é problematizar a televisão não como "vilã" midiática, destruidora de "heterogeneidades" e formadora de ideologia de consumo, mas como um campo de agenciamento de sentidos, além de verificar como os discursos, que a partir dela emergem, são capazes de nos influenciar positiva ou negativamente. A televisão ocupa um lugar expressivo e importante nos lares brasileiros, sua programação, apesar de ser diversa e fragmentada, ainda é vista com uma certa ligação com sua função de gênese, quando o objetivo era apenas o de informar e entreter.

Há de se pensar como os meios de comunicação, mais especificamente a televisão, descrevem a realidade, tendo em vista que ela atua nas três principais áreas de programação. Certamente é instigante pensar logo em seguida sobre quais efeitos/sentidos essas informações produzem nas sociedades que se informam de si próprias dessa maneira. Sobre essas questões Niklas Luhmann (2005, p. 130) nos diz:

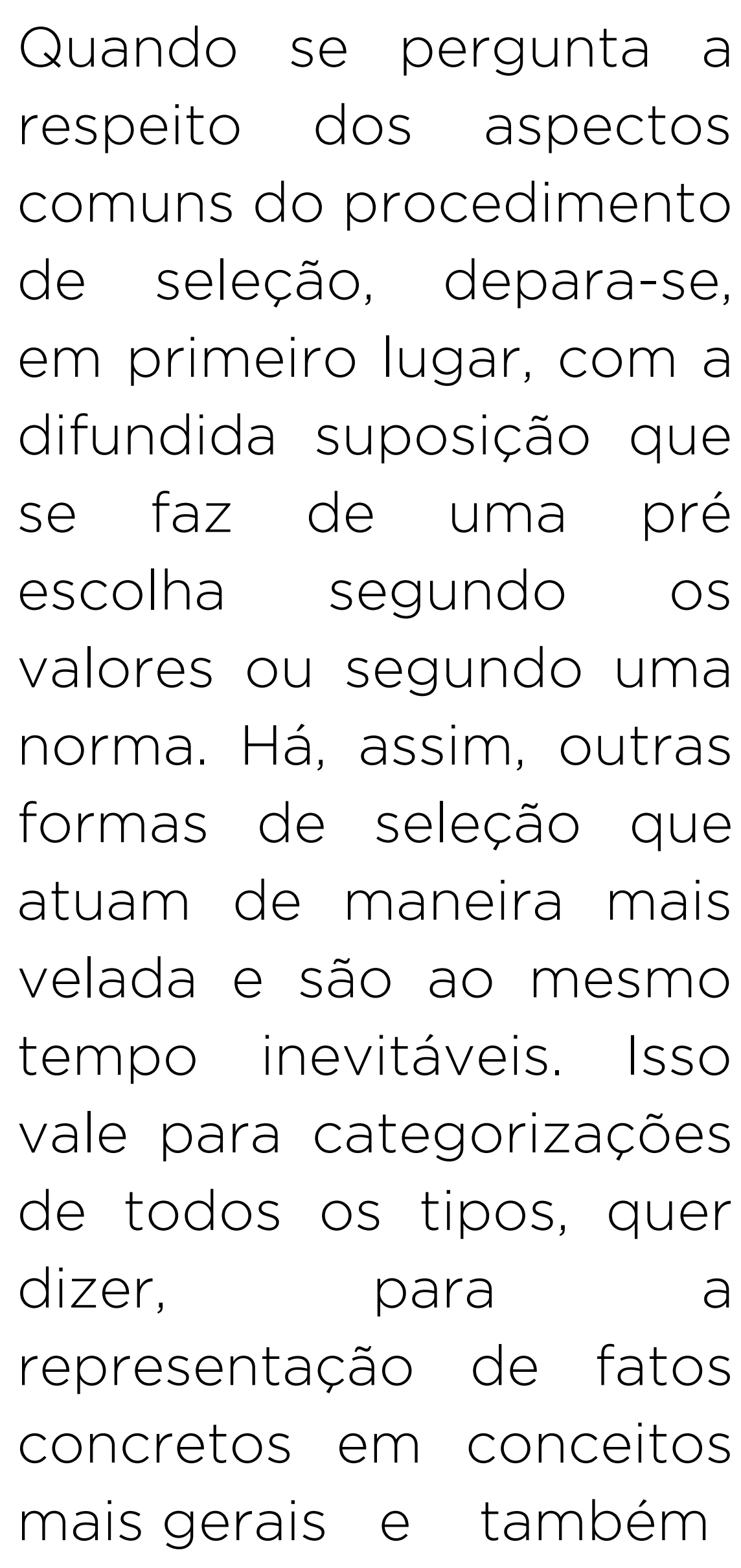

para as atribuições causais, a saber, para a representação simultânea de causa e/ou efeitos de cada fenômeno tratado.

Dessa forma, é pertinente pensar sobre os sentidos que a programação televisiva produz e principalmente sobre que realidade esses sentidos criam no telespectador. Para Luhmann (2005), os meios de comunicação, com suas constantes construções de realidade, jogam por terra 0 conceito até hoje dominante de liberdade. A liberdade continua sendo entendida como direito natural, como ausência de coerções. Essa suposta ausência de coerções é principalmente o conceito do senso comum. No entanto, sabemos que $\mathrm{O}$ discurso televisivo delimita nossa suposta "liberdade". Ainda na esteira da lógica de pensamento de Niklas Luhmann e articulando com a televisão como principal meio de comunicação utilizado pelos brasileiros, destacamos:

A inocência social dos
meios de comunicação,
seu caráter inofensivo,
baseia-se no fato de que
eles não forçam ninguém
a nada. Isso vale para
todas as suas áreas de
programáticas,
principalmente para a
publicidade.
realidade, contudo, a
liberdade baseia-se nas
condições cognitivas da
observação er da
descrição de alternativas
que mostram um futuro
aberto, a ser decidido,
mas, por isso mesmo,
desconhecido
(LUHMANN, 2005 , p.
144).

A televisão e suas mensagens devem ser consideradas como produtos da sociedade na qual vivemos por ser produzida por esta sociedade. Sendo produto dessa sociedade, revela como essa sociedade se organiza, quais são seus valores e quais são seus costumes. Ao nosso ver, a televisão, como principal veículo da "cultura de massa" no Brasil, constitui uma subteia que necessitaria de mais ações culturais (de significados) a fim de permitir que seus conteúdos, ou suas mensagens, não se perdessem nesse emaranhado de informações que nos bombardeiam nesses tempos em que vivemos uma "cultura da mídia".

A televisão, como veículo difusor de informações, que leva ao público novidades, imagens, divertimento, publicidades, fazse fundamental no processo de produção de sentidos e na formação do imaginário. Ela amplia a própria realidade, dando espaço para um ambiente simulado, espetacularizado. A televisão, no momento em que vai noticiar um fato e quer seduzir o espectador, utiliza-se de numerosos recursos tecnológicos, entre os quais se encontra a dramatização ou simulação. Um dos principais motivos para se dramatizar a notícia é torná-la urgente, mesmo que no dia seguinte não seja mais lembrada e não tenha mais relevância.

Dominique Wolton (1996), em o Elogio do grande público: uma teoria crítica da televisão, chama a atenção para algumas características muito importantes da televisão, que são a continuidade e a mistura diversificada de imagens, cuja "recepção e interpretação ninguém domina".

A televisão caracteriza-se como um meio bem particularizado. A recepção e a interpretação das 
imagens são feitas de forma individual por um grande público anônimo, pois as pessoas recebem em lugar privado imagens sobre o mundo. Logo, nem sempre os significados das imagens e/ou som que o autor queria passar para o público é absorvido. "Na televisão, o significado vai além da intenção na maior parte do tempo" (WOLTON, 1996, p.68).

Wolton afirma que a televisão possui papel antropológico fundamental de estruturar a identidade brasileira, por isso ela é o principal instrumento de percepção do mundo da grande maioria da população. "A televisão contribui diretamente, portanto, para retratar e modificar as representações do mundo" (1996, p. 69). Neste sentido, estudar as representações sociais emanadas pela televisão é algo instigante e nos faz perguntar mais especificamente que efeitos de sentidos, por exemplo, as imagens humorísticas dos negros causam e configuram no seio social.

A televisão constitui uma espécie de calendário/agenda para a grande parte dos telespectadores brasileiros; ela transmite informação e leva o espectador a se interessar pelo que está acontecendo no mundo à sua volta: esporte, ficção, jogos, telejornais. A isto se assoma o fato de o espectador buscar este veículo como forma de entretenimento. Deve-se lembrar que a grade de programação de uma emissora de televisão geralmente é composta por diversos gêneros.

O gênero do humor televisivo é o que nos interessa aqui. Luhmann (2005) nos diz que o entretenimento nos meios de comunicação deve atuar de forma indireta naquilo que é construído como realidade. No entanto, nesse aspecto, observamos de maneira geral que o humor televisivo atua de forma direta na construção da realidade pelos telespectadores, ou pelo menos há um certo emaranhado entre o real e o ficcional, já que muitas vezes as personagens desse humor televisivo se tornam populares e reverberam com muita força estereótipos e representações negativas de determinados grupos sociais. "Quanto maior for o papel da televisão, tanto mais a comunicação apoia-se no conhecimento implícito, daquilo que nunca pode ser comunicado" (LUHMANN, 2005, p. 137).

\section{NEGRITUDE \\ NA TV: O BORRAMENTO ENTRE O RISO E O RISÍVEL}

O ato de rir sempre foi considerado inerente ao homem e quase sempre esteve vinculado ao estado de felicidade ou como válvula de escape para relaxar e esquecer os problemas tidos como sérios. Bergson (2001), em sua obra 0 Riso: ensaio sobre a significação da comicidade, nos traz abordagens elucidativas sobre o riso/humor, dentre elas elencamos três questões para dialogar nesse processo de entender o riso no humor. Para Bergson (2005), o ato de rir, em primeiro lugar, é um fenômeno social, ou seja, nosso riso é sempre o riso de um grupo. Em segundo lugar, o riso esconde uma segunda intenção de entendimento, quase de cumplicidade, com outros ridentes, reais ou imaginários; e, por último, Bergson nos diz que na sociedade existe uma vigilância constante que procura atitudes, gestos, enfim, acontecimentos que fujam de um padrão social, daquilo que saia do centro gravitacional, conforme suas palavras, do cotidiano e se torna uma excentricidade.

Quando Bergson diz que o riso é um fenômeno social é porque, para o teórico, o riso está atrelado ao contexto cultural da sociedade que ri. Por isso, o que pode ser engraçado para determinada sociedade não o é para outra. Nesse sentido, a piada dita só terá sentido de "engraçada" se estiver relacionada com o contexto sociocultural dos ouvintes/assistentes. No segundo caso, Bergson (2001) nos explica que a risada é um instrumento poderoso, um campo no qual é possível construir discursos, críticas, determinados pontos de vista e expressar ideias de formas maquiadas de humor. A risada é derivada de elementos socioculturais nos quais o objeto da piada carrega consigo uma carga histórica de características de conhecimento que circula pelo imaginário social.

Na última sentença a ser considerada, o riso é entendido como trote social, constituindose, portanto, numa forma de enquadramento social sobre o ato de rir daquilo que não faz parte do senso de normalidade instalado. Podemos citar como exemplo o ato de rir de alguém que tropeça na rua; esse ato de tropeçar é excêntrico e foge da normalidade. O riso, neste caso, está associado não somente ao movimento involuntário da pessoa, sujeito da queda, mas à sua desatenção, a um erro no seu movimento, à sua falta de 
agilidade ou equilíbrio; tal falha possibilita a queda e a risada surge como um gesto social que o filósofo atribui a uma correção, um aviso de atenção. Em nosso estudo, especificamente, interessa-nos encarar o riso como um gesto que se encarrega desse papel de reprimir excentricidades, corrigir defeitos. Sempre um pouco humilhante para quem é seu objeto, o riso é de fato uma espécie de trote social. Dito isto, vamos adentrar no riso emanado dos programas de humor televisivos, mais especificamente do riso e do humor, veiculados por meio de personagens negros.

Com a prerrogativa de que "tudo pode" e/ou da licença poética da sátira[3] que é inerente ao humor, as imagens televisivas têm se apropriado dessas e de outras prerrogativas para compor/elaborar personagens de humor cujas características fenotípicas e sociais são apresentadas de forma caricata e desrespeitosa. Isso se dá de forma mais nítida quando analisamos as representações do negro em programas de humor da televisão brasileira.

A historiografia recente dessa temática nos mostra que o negro vem sendo sempre representando de forma inferiorizada e subalternizada pela mídia televisiva. Araújo (2000) chega a essa constatação em sua pesquisa sobre a representação do negro nas telenovelas brasileiras. Neste estudo, o autor observa que se percebe a presença de atores negros desde a gênese das telenovelas brasileiras, em especial na Rede Globo de Televisão. No entanto, os papéis destinados a esses atores na maioria das vezes são de personagens subalternos e secundários. No que diz respeito à classe e à posição social legitimadas como 'de sucesso'. Os melhores papeis sempre eram destinados a atores brancos. Dessa forma, Araújo (2000) constata que as posições de sucesso, de mando, de chefia ou de poder simbólico, de alguma forma, legitimavam o pensamento colonial brasileiro:

\begin{abstract}
Além da telenovela, podemos ver os reflexos dessa realidade nos comerciais de tevê. Aí percebemos as consequências do desinteresse histórico da elite brasileira em formar um mercado consumidor amplo, em seu próprio pais, e da preferência pela imigração de mão de obra europeia no período final da escravidão, em detrimento do trabalhador negro. Empresários, publicitários e produtores de tevê, como norma, optam pelo grupo racial branco, nos processos de escolha dos modelos publicitários, na estética da propaganda e até mesmo nos critérios de patrocínio ou apoio a projetos culturais (ARAUJO, 2000, p. 39)
\end{abstract}

No humor essas representações não são muito diferentes, pois o agravo situa-se na licença poética e na falta do cuidado com os direitos da pessoa humana o que, de certa forma, normaliza as piadas racistas e, principalmente, a figura imagética do negro, representada quase sempre como algo exótico e caricatural. Por isso a ideia de moralidade e realidade no humor é tão tênue, uma vez que o humor, raras vezes, lembra-se do senso de "moral", justiça e respeito à diversidade etnicocultural. maioria das vezes são de personagens subalternos e secundários. No que diz respeito à classe e à posição social legitimadas como 'de sucesso'. Os melhores papeis sempre eram destinados a atores brancos. Dessa forma, Araújo (2000) constata que as posições de sucesso, de mando, de chefia ou de poder simbólico, de alguma forma, legitimavam o pensamento colonial brasileiro:

Diante desse quadro, temos que admitir que há um certo borramento, há uma linha muito tênue entre o engraçado e o risível. No humor televisivo isso é exacerbado, tendo em vista que geralmente essas personagens, mesmo marcadas por traços que evidenciam preconceitos, caem no gosto popular. Acreditamos que isso acontece não por uma identificação da classe trabalhadora/popular com essas personagens e sim por um padrão estético-social criado em torno da figura do negro, espécie de contraponto ao projeto ideológico da elite brasileira, eugenista e racista. É certo que o humor de fato não lida com o que corriqueiramente passou-se a entender como 'politicamente correto'. Uma das questões que se coloca aqui é o modo como o discurso colonialista se perpetua através desses meios de representação.

As representações caricaturais do negro no humor da televisão brasileira acontecem há um certo tempo. Feita uma breve pesquisa historiográfica, encontramos alguns personagens com mais força, mas já com esse apelo racializado de maneira negativa. Personagens como Mussum[4], Vera Verão[5], Azeitona[6], Batista[7], Tião Macalé[8] e 
outros reforçam o estereótipo do negro sempre em posições humilhantes, vexatórias e de subalternidade; merecem destaque personagens como Mussum e Vera Verão, nos quais estão estampados rótulos de alcoólatra e uma sexualidade pervertida, respectivamente. Hall (2016) nos explica o conceito de estereotipagem:

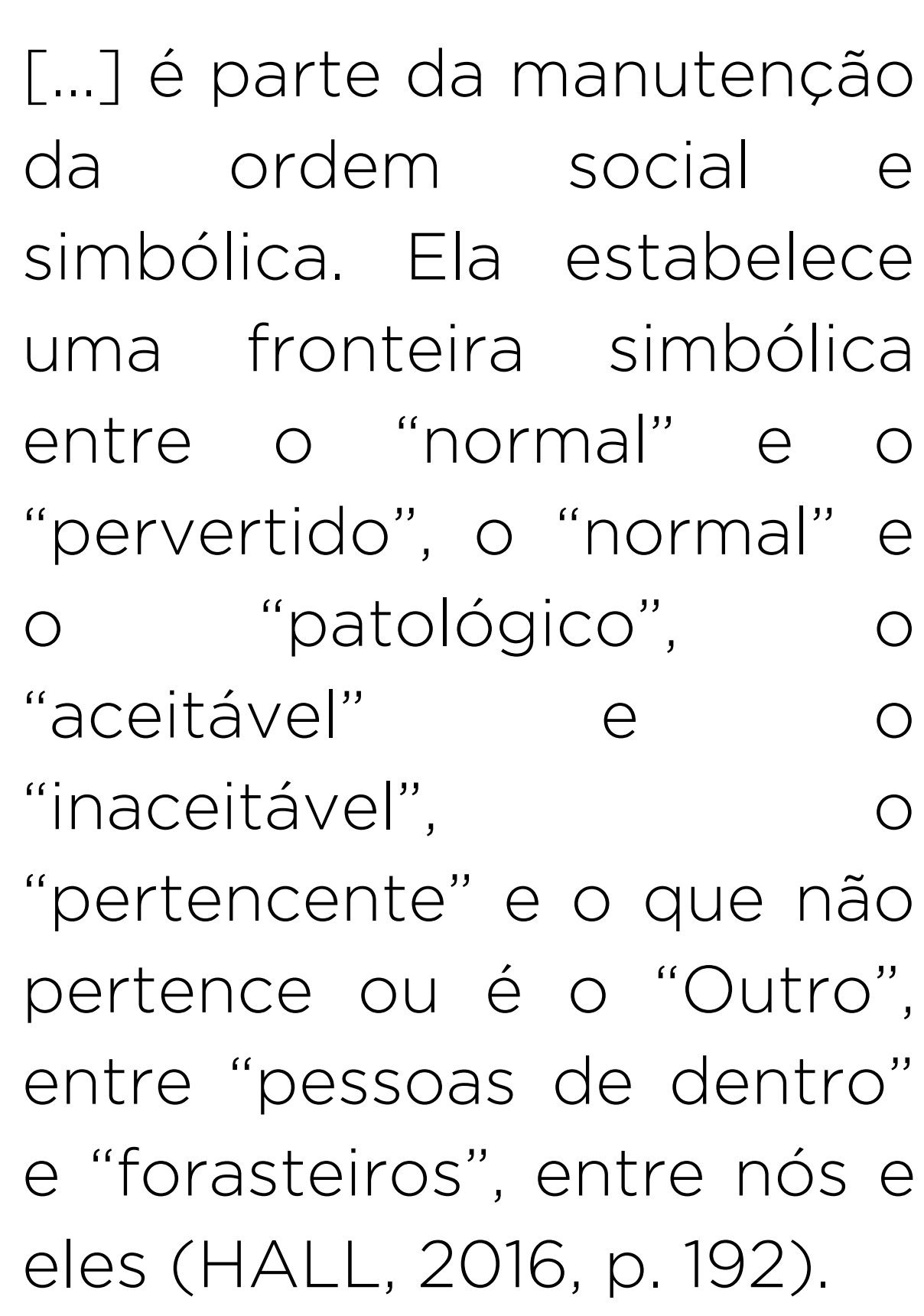

Dessa forma, podemos observar e denunciar o poder dessas representações do negro no humor quando elas acontecem de forma estereotipada. A estereotipagem é uma violência simbólica e faz parte do regime de representação em que vivemos; por isso ela classifica, marginaliza e determina maneiras de representar alguém ou algo, e é a partir dessa perspectiva que iremos analisar a representação do negro no humor televisivo, mais particularmente em Adelaide.

\section{ADELAIDE! \\ É PRA RIR OU PRA CHORAR?}

Na esteira do que preconiza a análise do discurso e a partir de uma análise criteriosa no quadro humorístico, pretendemos, neste tópico, descrever e analisar a personagem Adelaide, a partir de dois episódios: o primeiro exibido em 12/05/2012[9] e o último exibido em 29/06/2013[10]. O objetivo aqui é discutir como as representações e os discursos, ora explícitos, ora velados, emanados pela personagem, estão carregados de estereotipagem (Hall, 2016) e aspectos subalternizadores em relação à população negra. A escolha desses episódios se deu para que seja analisada a gênese do quadro de "Adelaide" e as possíveis transformações que ele passou até chegar ao seu episódio derradeiro, o qual também é nosso objeto de análise.

Para dar conta dos discursos velados gerados a partir do "riso", encaramos a televisão como um objeto discursivo. Por essa razão, caminhamos para o que dizem os pressupostos teóricos da Análise de Discurso, conforme iniciada na França por Pêcheux (1997, 1997a, 1990), na década de 1960, e desenvolvida no Brasil por Orlandi (2001; 2001a) e diversos pesquisadores, sobretudo da área de Linguística. Nesta perspectiva teórica, o discurso, e também o discurso televisivo, é compreendido como "efeito de sentidos entre locutores" (PÊCHEUX, 1997a), efeitos estes determinados pelas condições de produção em que são constituídos, formulados e postos em circulação.

A compreensão do discurso televisivo, em seus processos de constituição, formulação e circulação, contribui para refletir sobre a televisão não apenas como uma simples tecnologia voltada à transmissão de imagens e sons, mas como participante dos processos de constituição/produção de sentidos na sociedade.

Analisaremos a seguir os dois episódios, buscando demonstrar como as categorias de inferioridade e subalternidade estão presentes no discurso oral proposto pelo programa, ainda, destacamos como fio condutor da análise o discurso visual emanado pela caracterização da personagem. Dessa forma, a análise de discurso centra-se em discutir os efeitos de sentido provocados pelas falas da personagem em questão, considerando o contexto e o enredo em que

os programas foram criados. Vamos à análise.

O humorístico Zorra Total, transmitido semanalmente pela emissora Rede Globo, ficou no ar por 16 anos (de 25 de março de 1999 a 14 de maio de 2015), contou com mais de 600 episódios, e, depois de uma pausa, atualmente compõe novamente a grade de programação da emissora, com um novo nome e novos quadros e roteiro intitulado: Zorra.

Durante a reestruturação levada a cabo no ano de 2015, percebe-se uma nova abordagem de humor, resultando praticamente em um outro programa. A manutenção de parte do título, Zorra, se deu graças ao forte apelo do nome perante $O$ público e os anunciantes. Este humorístico se estabeleceu nas noites de sábado como líder de audiência, porém, nos últimos anos, foi perdendo uma considerável parcela de seu público, por diversos fatores: seja pela própria qualidade do conteúdo do programa, seja pela maior exigência do seu público e também pelo crescimento da TV paga, que cada vez mais se torna um produto acessível para classes menos favorecidas, normalmente as classes que engrossavam a audiência do Zorra Total. 
A personagem em questão, Adelaide, fazia parte do Programa Humorístico Zorra Total e ficou no ar de 2012 a 2013, interpretada pelo ator Rodrigo Santana. A personagem caiu no gosto popular de maneira rápida e fácil e logo se viu nas ruas e nas redes sociais com o uso de seu principal bordão "me dá um centarro!". Adelaide é uma mulher negra, com características fenotípicas exageradas,

roupas extravagantes, os dentes são comprometidos, tem um marido que faz o tipo "malandro e cachaceiro", possui três filhos e seu ambiente de cenário encontra-se situada no metrô, onde ela pede dinheiro/esmola aos passageiros.

Apesar de citar os filhos e o marido, duas dessas personagens só existem virtualmente, compondo de fato o quadro junto com Adelaide apenas seu marido (também interpretado por Rodrigo Santana) e sua filha caçula Brit Sprit (interpretada pela atriz Isabella Marques). É importante ressaltar que a personagem Brit Sprit é construída com o mesmo estereótipo, quase um duplo, de sua mãe, apresentando uma estética negra que deprecia e ridiculariza a população negra do país.

Outra caraterística marcante na personagem é a pronúncia arrevesada das palavras, fora do padrão da norma gramatical do falante da classe média brasileira, o que indica o baixo grau de instrução de Adelaide, fato que provavelmente a aproxima à grande parte de nossa população e, por isto, atinge $O$ senso comum dos brasileiros em relação à imagem da pessoa negra. Percebe a partir dessas características, de imediato, a associação à falta de escolaridade ou até mesmo a ideia de incapacidade intelectual dos sujeitos negros. Essas interpretações se ratificam, no senso comum do cotidiano, quando ouvimos algumas opiniões em relação às cotas universitárias para negros e indígenas.

O figurino da personagem Adelaide não é uma criação de Rodrigo Santana. A personagem foi constituída por ele para performance teatral, porém foi readaptada para o humorístico Zorra Total, de modo que correspondesse à estética do humorístico, que devia enfatizar - caricatural e o grotesco, utilizando-se da técnica do blackface[11], estilo teatral criado nos Estados Unidos para representar os negros, quando esses ainda eram proibidos de atuarem ou interpretarem papéis de destaque. O blackface representa uma imagem exacerbada e depreciativa do fenótipo negro, segundo a ótica dos brancos quando estes se pintavam de preto e realçavam seus lábios de vermelho, ridicularizando as características da pessoa negra..

No primeiro episódio em questão, a personagem entra em cena pedindo licença e também pedindo dinheiro: "Cunricença, será que a senhora tem cinquenta centarro, vinte e cinco centarro ou dez centarro, p'a eu compra um leite pra minha filha mais nova: a Cráudia!". A personagem segue pedindo e evita pedir dinheiro para algumas pessoas porque, segundo ela, "tem cara de pobre". Nesse sentido, podemos perceber o sentido do humor quando a pedinte que está sendo julgada pelos olhares e pela mendicância passa a ser a pessoa que dá dinheiro e que julga os outros. Como já exemplificamos anteriormente, - objeto da risada passa a ser o sujeito do riso.

O quadro segue e Adelaide encontra com sua interlocutora e começa contando uma história em que, numa enchente, ela queria muito salvar as palhas de aço, pois, sem elas não poderia lavar suas panelas, etc. Dado esse enunciado, a personagem começa a explicar que, ao ver uma palha de aço boiando na água, se aproxima dela, porém, na hora em que pega e puxa essa palha, percebe que na verdade aquilo era 0 cabelo de sua filha. É justamente esse tipo de humor que reforca a baixa estima estética da mulher negra. É evidente que esse tipo de piada também afeta os homens negros. Todavia, damos destaque aqui à mulher, pois, além da condição racial, existe, nesse caso, uma questão de gênero envolvida.

Analisando a estética e principalmente o discurso da personagem, percebemos uma carga de preconceito muito intensa. A linguagem visual e sonora que constituem a personagem são fatores que corroboram com o riso. O mais dramático ocorre quando, resultado da aparição de Adelaide, percebemos o negro rindo de outro negro. Hall (2016) explica isso através do que ele chama de política da estereotipagem:

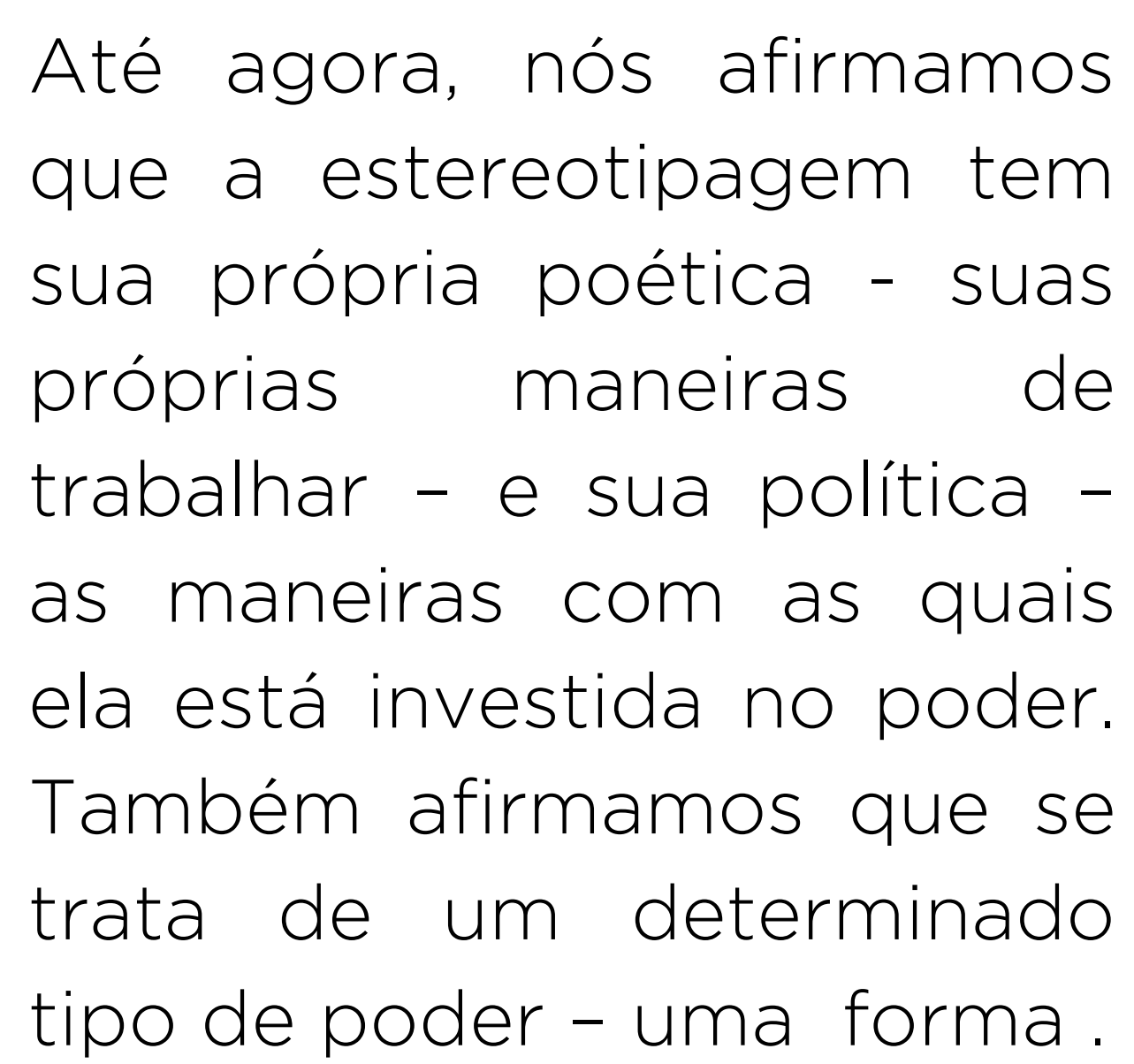

Até agora, nós afirmamos que a estereotipagem tem trabalhar - e sua política as maneiras com as quais trata de um determinado tipo de poder - uma forma. 
de poder hegemônico e discursivo que opera tanto por meio da cultura, da produção de conhecimento, das imagens e da representação, quanto por outros meios (HALL, 2016, p. 200)

O último episódio que foi ao ar tem como participantes, além de Adelaide e sua filha Brit Sprit, os atores comediantes Paulo Silvino e Tony Tornado. De pronto já é possível fazer uma inferência sobre a colocação do ator Tony Tornado, ele é negro e faz o papel de assessor político de deputado interpretado por Paulo Silvino. Resultado das várias críticas dos movimentos sociais a respeito do quadro, percebe-se a personagem de Tony Tornado, vestido em elegante terno, como uma tentativa de apaziguamento

ou de recolocação da figura do negro no quadro. No entanto, Hall (2016) afirma que as representações são criadas socialmente, por isso a imagem de um homem de terno está legitimada social e culturalmente; afinal, no imaginário social brasileiro, o terno liga-se a um status privilegiado, 'de elite', como alguém de sucesso ou que ocupa uma posição de mando, dessa forma, a imagem de um homem negro de terno na verdade foi só uma tentativa de atenuar e abrandar as críticas ao quadro.

A ambientação do quadro se dá de forma muito parecida com as anteriores, Adelaide encontra-se no metro com sua filha, e lá no meio de todas as pessoas a cena se inicia, Adelaide, escolhe sua "vítima" e faz seu jogo dramático e direto para conseguir dinheiro, é nesse momento que se depara com o personagem de Paulo Silvino
(Politico). Junto a Paulo Silvino temos numa posição secundaria em cena o personagem de Tony Tornado (Assessor político), é nesse contexto que Adelaide começa a tecer uma certa crítica a determinados comportamento não tão éticos de nossos políticos, no entanto, logo em seguida também age com falta de ética quando tenta enganar as pessoas que Ihe ajudavam de alguma forma. É importante ressaltar que a personagem critica políticos corruptos, no entanto esquecese que uma atitude do dia a dia também pode ser considerada corrupta.

Nesse episódio, o país vive uma crise política e a personagem faz referência a pagamentos de propinas, fato quase comum na política brasileira. $\bigcirc$ que é interessante é o sentido que isso produz no quadro; as personagens estabelecem uma relação entre propina e esmola, logo, podemos inferir que Adelaide também tem 0 estereótipo da esperteza 'à brasileira'. Além disso, a personagem relata a compra de um fogão de última geração, fato esse que reforça a ideia de que a pedinte engana as pessoas sobre sua condição financeira, além de alimentar a ilusão das camadas populares em ascender para a classe média brasileira.

A estética da personagem revela a manutenção do estereótipo grotesco e subalternizado do negro, e, apesar das críticas, não se percebe uma certa atenuação nesse sentido. Entretanto, percebeu-se uma diminuição de tempo do quadro em relação ao primeiro episódio e os demais. Destaca-se aqui a fala de Adelaide que apresenta desvios grotescos em relação à norma padrão do falante brasileiro, em conformidade com o que foi comentado anteriormente. Os bordões da personagem revelam sentidos e discursos depreciativos e debochados, como "a cara da riqueza”, e as representações de quem é pobre e quem não é, mas, acima de tudo, evidencia uma imagem e uma representação cultural do negro de forma caricata e danosa no sentido moral, ético e estético.

Por fim, é importante destacar que, embora todos esses elementos étnicos se façam presentes nesse quadro humorístico, a estratégia discursiva do programa induz ao fato de que todas essas questões vivenciadas ali são resultado de um problema de classe, dissociados de quaisquer questões de ordem política ou econômico social. Dessa forma, o quadro "Adelaide, a mendiga do metrô", nega, por meio da estratégia humorística, essa gama de desigualdades vivenciadas pela população negra e, mais especificamente, a mulher negra, que tem como adicionais as desigualdades nas relações de gênero. Tal direção está ratificando 0 mito da democracia racial que se instaurou na sociedade brasileira.

\section{CONSIDERAÇÕES}

\section{FINAIS}

O humor televisivo e a representação da imagem dos sujeitos negros nos meios audiovisuais de forma depreciativa e em papéis que são criados como subalternos e/ou secundários não é algo novo, mas sim um problema histórico. Construído desde os 
tempos coloniais, ao longo do tempo, o racismo no Brasil contemporâneo atua através de diversos mecanismos, sejam eles materiais e/ou simbólicos; de forma consciente ou inconsciente. Após mais de um século da abolição da escravatura, a diversidade étnica cultural em nosso país, ainda hoje, é uma das grandes questões a serem debatidas. Daí a importância de elas estarem em pauta nas abordagens e pesquisas acadêmicas.

Existe uma ideia errônea por parte de algumas pessoas de que o humor televisivo brasileiro do passado não caracterizava os negros por meio de discriminações e preconceitos, crença equivocada de que o humor antigamente era inocente e motivado apenas pelo divertimento. Uma interpretação errônea que precisamos superar. O que de fato aconteceu, sobretudo nas últimas duas décadas, foi uma maior reivindicação por parte dos movimentos sociais em relação aos direitos civis das ditas minorias. A luta por igualdade possibilitou uma maior visibilidade para causas que afetam grupos sociais histórico, social e politicamente desvalorizados.

No caso específico de Adelaide, percebemos que a personagem representa, de forma etnocêntrica e inferiorizada, a população negra do país. É certo que os grupos e movimentos sociais reivindicaram a retirada da personagem; no entanto essas representações sociais e imagéticas do(a) negro(a) perpetuam-se graças à falsa ideia de democracia racial, de que falamos anteriormente e vai ao encontro daquilo que
Munanga (2008) chamou de mestiçagem. A mestiçagem, de alguma forma, fez com que os não negros quisessem ser "brancos", e isso enfraqueceu a desejada identidade cultural negra. A maioria dos afrobrasileiros está familiarizada com a ordem estabelecida pela produção simbólica das redes de televisão, marcada por referências eurocêntricas e, consequentemente, excludentes.

Contudo, ainda assim, não deixa de ser sintomático que os mecanismos ideológicos da televisão prevaleçam sobre o discurso antirracista e propositivo, defendido como 'bandeira de reivindicação' dos movimentos negros. $O$ alcance da televisão como mídia de entretenimento das massas dificulta o combate ao racismo quando opera com formas de linguagem que reproduzem e fortalecem, no imaginário social, questões históricas que contribuem para uma visão pejorativa da população negra, visão que é capaz de inserir até mesmo na própria pessoa negra uma visão colonialista, que atua no inconsciente coletivo e no imaginário social de negros e não negros brasileiros. O humor é um recurso discursivo que nada tem de ingênuo; ele está a serviço das elites dominantes, racistas e injustas, que se utilizam da televisão para apregoar desigualdades e reiterar, através do riso, seu domínio em relação à maioria da população brasileira que, cada vez que ri de Adelaide, desmantela-se a si mesma e ajuda a maquiar a cara do Brasil.

\section{NOTAS:}

[1] Maior levantamento sobre os hábitos de informação dos brasileiros, a "Pesquisa Brasileira de Mídia 2015" (PBM 2015) revela que a televisão segue como meio de comunicação predominante entre os brasileiros. Revelou ainda que o brasileiro já gasta cinco horas do seu dia conectado à internet e que os jornais são os veículos mais confiáveis. Encomendada pela Secretaria de Comunicação Social da Presidência da República (SECOM) para compreender como o brasileiro se informa, a PBM 2015 foi realizada pelo IBOPE com mais de 18 mil entrevistas.

[2] Linha tênue entre uma coisa e outra. O que fica borrado.

[3] Sátira, para o dicionário Dicionario on line, é "composição poética cujo objetivo é ridicularizar vícios e/ou comportamentos" (acesso no dia 29 de abril de 2020, https://www.dicio.com.br/satira/). Do conceito da literatura, guardadas as devidas proporções, podemos estender o sentido para os programas televisivos.

[4] Personagem do humorístico "Os Trapalhões", transmitido pela Rede Globo de Televisão e interpretado por Antônio Carlos Bernardes.

[5] Personagem do humorístico "A Praça é Nossa", transmitido pelo SBT e interpretado por Jorge Lafon.

[6] Personagem do humorístico "A Praça é Nossa", transmito pelo SBT e interpretado por Bui.

[7] Personagem do humorístico "A Escolinha do Professor Raimundo", exibido pela Rede Globo de Televisão e interpretado por Eliezer Mota e mais tarde por Rodrigo Santana.

[8] Personagem interpretado por Augusto Temístocles da S. Costa, especialmente no programa "Os Trapalhões", da Rede Globo de Televisão.

\section{[9] (ADELAIDE, 2012).}

[10] (NÃO É SÓ..., 2013). 
[11] Estilo teatral criado nos Estado Unidos para representar os negros, nessa época os negros eram impedidos de atuar, por isso os atores brancos pintavam seus rostos de preto e interpretavam os papéis negros

\section{REFERÊNCIAS}

ADELAIDE - A Cara da Riqueza. Publicado no YouTube.

15 maio 2012. 1 vídeo (4 min.). Disponível em: https://cutt.ly/hyPny2r Acesso em: 20 jun. 2017.

ARAÚJO, Joel Zito Almeida de. A negação do Brasil: o negro na telenovela brasileira. São Paulo: Editora SENAC São Paulo, 2000.

BERGSON, Henri. O Riso: ensaio sobre a significação da comicidade. São Paulo: Martins Fontes, 2001.

BRASIL. Presidência da República. Secretaria de Comunicação Social. Pesquisa brasileira de mídia 2015: hábitos de consumo de mídia pela população brasileira. Brasília: Secom, 2015

HALL, Stuart. Cultura e Representação. Rio de Janeiro: Editora PUCRio/Apicuri, 2016

Da Diáspora: identidades e mediações culturais. Belo Horizonte: Editora UGMG, 2013.
KELLNER, Douglas. A cultura da mídia. Bauru, São Paulo: EDUSC 2001.

LUHMANN, Niklas. A Realidade dos Meios de Comunicação. São Paulo: Paulus, 2005

MUNANGA, Kabengele. Rediscutindo a mestiçagem no Brasil: identidade nacional versus identidade negra. Belo Horizonte: Autentica, 2008

NÃO É SÓ POR 'CENTARRO'. Adelaide pede dinheiro a político no metrô. Publicado no GloboPlay. 29 jun. 2013. 1 vídeo (5 min.). Disponíve em: https://cutt.ly/ryPnpNK Acesso em: 29 jun. 2017

ORLANDI, Eni P. Análise de discurso. Princípios e procedimentos Campinas: Pontes, 2001.

Discurso e texto: formulação e circulação dos sentidos. Campinas: Pontes, 2001a.

PÊCHEUX, Michel. Semântica e discurso: uma crítica à afirmação do óbvio. Campinas: Editora da Unicamp, 1997

Análise automática do discurso (AAD-69). In: GADET Françoise; HAK, Tony (Org.) Por uma análise automática do discurso. Campinas: Editora da Unicamp $1997 a$.
WOLTON, Dominique. Elogio do Grande Público: uma teoria crítica da televisão. São Paulo: Ática, 1996.

\section{Artigo recebido em: 19 Jul 2019 I Artigo aprovado em: 02 Maio 2020.}

[i] Doutor pelo Programa de Pós-Graduação em Comunicação, Linguagens e Cultura (PPGCLC/UNAMA), Mestre pelo PPGARTES/ICA/UFPA, Especialista em Arte-Educação, Especialista em História das Culturas Afro-brasileira e Indígena e Licenciado Pleno em Artes Visuais e em Pedagogia pela UNIFAP/AP. Professor das Redes Estadual e Municipal de Ensino do Estado do Amapá e Professor da Faculdade Madre Tereza - FAMAT-AP.

Orcid: http://orcid.org/0000-0003-2356-7926

E-mail: bscosta82@hotmail.com

[ii] Professor da Universidade da Amazônia (UNAMA): graduação em Letras e Programa de Pós-Graduação em Comunicação, Linguagens e Cultura (PPGCLC). Doutor em Letras pela PUC-MG. Integra os grupos de pesquisa e estudos Narramazônia: narrativas contemporâneas na Amazônia Paraense (UFPA/UNAMA), Academia do Peixe Frito (UNAMA/ UFPA), CUMA Imaginário amazônico (UEPA) e Makunaíma: literatura latino americana (UFPA); curador do acervo Dalcídio Jurandir projeto Moronguetá/Landi (FAU-UFPA). Autor, entre outros de Traço-Oco (Penalux, 2018), semifinalista do prêmio Ocenaos de Literatura.

Orcid: http://orcid.org/0000-0001-7238-702X

E-mail: pontedogalo3@gmail.com

[iii] Professora da Universidade Federal do Para (UFPA): graduação em Comunicação Social e Programa de Pós-Graduação Comunicação, Cultura e Amazônia (PPGCOM). Doutora em Comunicação pela Universidade Federal Fluminense (UFF), Mestre em Planejamento do Desenvolvimento pelo Núcleo de Altos Estudos Amazônicos (NAEA/UFPA). É uma das coordenadoras dos projetos Narrazonia (UFPA/UNAMA) e Academia do Peixe Frito (UNAMA/UFPA).

Orcid: https://orcid.org/0000-0002-0493-8763

E-mail: vaniatorrescosta@gmail.com 